\title{
Mechanical devices to control, limit and attenuate shocks, vibrations and seismic movements in buildings, equipment and piping networks
}

\author{
V. Serban, A. Panait \& M. Androne \\ Subsidiary of Technology and Engineering for Nuclear Projects, \\ Bucharest-Magurele, Romania
}

\begin{abstract}
This paper presents new types of mechanical devices, developed by SITON in cooperation with other units in Romania, by means of which to control, limit and damp shocks, vibrations and seismic movements in buildings, equipment and pipe networks.

The new devices, called "SERB-devices", can overtake static loads over which dynamic loads may overlap and be damped. The devices allow "cuttingoff" the dynamic action in-coming from the environment to the protected systems (building, equipment, pipe network, etc) and the overtaking of shocks and vibrations generated by the systems to protect the environment. The devices may have high relative displacements, with or without elastic reaction force, thus allowing the performance of a good isolation of the components against the dynamic action, also overtaking the displacements due to thermal expansions or support yielding.

The devices are made of materials that practically are not affected by the aging phenomenon and relative large temperature variations and may be guaranteed throughout the service-life of each unit, without maintenance or repair. The devices are small in size if compared with the existing ones for similar performances. The radiation resistance capacity is very good and therefore allows their use in nuclear-power plants.
\end{abstract}

Keywords: shocks, vibrations and seismic movement, isolation of the systems, control, limitation and damping, base isolation systems. 


\section{Introduction}

Buildings, equipment and pipe networks are generally affected by shocks and vibrations generated by the operation of equipment or fluid flow through pipe networks. Additionally, on sites with average or high seismic activity, seismic movements need to be considered in the design of equipment, pipe networks and buildings.

Such shocks and vibrations affect the proper operation of the technological equipment and components, damage the buildings' structure where they are installed in and generate waves and noises that propagate to the environment, affecting the foundations of sensitive equipment and components, and also generate a discomfort for the operation personnel and for the occupants of buildings.

Function of their generating source, shocks and vibrations evidence strong different dynamic characteristics and the elimination or reduction of their effects may be obtained only by special solutions applicable to each individual case, after having analyzed excitation kinetic characteristics.

This paper is a presentation of SERB-SITON solution application to enhance the safety level of components against shocks, vibrations and seismic movements. The new SERB supports and devices for components are developed on basis of the Romanian Invention Patent no. 119845 (Serban [1]), now in process of being internationally protected.

The first industrial application related to shock and vibration reduction was in 2003. It was aimed to isolate a $1250 \mathrm{Kg}$ forging hammer located in the Forging Workshop (IUS - Brasov, Romania) and the inlets and outlets pressurized air pipe [2].

The next applications were: another $1250 \mathrm{~kg}$ forging hammer from IUSBrasov; the strengthening of a ground floor and 5-stories building with reinforced concrete frame structure (NAVROM Galati-Romania) and the isolation of 5 electrical cabinets from Heavy Water Production Plant in DrobetaTurnu Severin, Romania, etc.

SERB supports and devices are certified in Romania by TECHNICAL AGREMENT 016-03/144-2005 [3].

\section{The system response to dynamic actions}

The effect of shocks, vibrations and seismic movements on buildings, equipment, pipe networks, etc. herein called "systems", is dependant both on the intensity of the dynamic action and the response of the systems at dynamic actions. The excitation may transfer to the system, a quantity of energy per oscillation cycle equal or smaller than the energy corresponding to one oscillation cycle, function of the harmonization or dies-harmonization of the system Eigen motion with the dynamic action. In order to see how may be reduced the total dynamic loading (action + response) acting to a system, the authors analyzed the behaviour of the dynamic response on a SDOF oscillating system in-frequency domain, subjected to a harmonic dynamic action, (Serban 
et al [4]). Consider a simple SDOF oscillating system with a mass, $m$, damping, $c$, (proportional to the vibration velocity) and stiffness, $k$, (proportional to the relative displacement). The oscillating system is subjected to an oscillating movement of the support, marked by $u_{s}(t)$, that, in the analysis, is approximated with a harmonic $T_{s}$ period movement, with the form:

$$
u_{s}(t)=A \sin \Omega t, \Omega=\frac{2 \pi}{T_{s}}
$$

The motion equations of the oscillating system, written in terms of relative displacement, $x(t)$ and the total displacement, $y(t)$, respectively, are:

$$
\begin{gathered}
\ddot{x}(t)+2 \beta \omega \dot{x}(t)+\omega^{2} x(t)=a \sin \Omega t \\
\ddot{y}(t)+2 \beta \omega \dot{y}(t)+\omega^{2} y(t)=\omega^{2} A \sin \Omega t+2 \beta \omega A \Omega \cos \Omega t
\end{gathered}
$$

with the initial conditions: $x(0)=0, \dot{x}(0)=-v_{0} ; y(0)=0, \dot{y}(0)=0$

where $v_{0}$ - the relative velocity in the initial moment that is equal and in opposite direction with the support velocity at $t=0, \beta$ - critical damping ratio; $\omega$ - angular frequency.

The amplitudes of the kinetic and elastic energies specific to the mass of the oscillating system versus the source energy amplitude $\mathrm{E}_{\mathrm{s}}$, (Serban et al [5]), are:

$$
\left|E_{c}\right|=\frac{\left(r^{2}+4 \beta^{2}\right) r^{2}}{\left(r^{2}-1\right)^{2}+4 \beta^{2} r^{2}} \cdot\left|E_{s}\right|,\left|W_{p}\right|=\frac{r^{2}}{\left(r^{2}-1\right)^{2}+4 \beta^{2} r^{2}} \cdot\left|E_{s}\right|
$$

For an oscillating system respond to dynamic loads with smaller or equal amplifications than the static loads of the same intensity (without amplification) it is necessary that the amplitude of the kinetic and elastic energy built-up in the oscillating system, be smaller or equal with the excitation energy: $\left|E_{c}\right| \leq\left|E_{s}\right|$ and $\left|W_{p}\right| \leq\left|E_{s}\right|$. For the kinetic energy the relation is: $r=\frac{\omega}{\Omega} \geq \frac{1}{\sqrt{2}}$, or $\frac{T}{T_{s}} \geq \sqrt{2}$, irrespective of the oscillating system damping.

The condition that the maximum elastic amplitude energy of the oscillating system is smaller or equal with the maximum amplitude energy of the source per oscillating cycle is dependent on the oscillating system damping and it corresponds to an oscillating system vibration period greater than $1.41 T_{s}$. Figs. 1 and 2 illustrate the variation of the kinetic and elastic energy amplitude of an oscillating system for $\beta=5 \%$ and $\beta=20 \%$. Analyzing the diagrams, it results that the most efficient solution to reduce the total energy of a system subjected to dynamic actions is to make an elastic connection with high damping at the level of the anchoring point.

a) For a 5\% damping of an oscillating system, the kinetic and elastic energy built-up in the system is 100 times greater than the energy of the excitation for resonance $T=T_{s}$ and only about 10 times greater at the 
system vibration period, which is different from the excitation oscillation period by $\pm 20 \%$.

b) For a $20 \%$ damping of the oscillating system, the kinetic and elastic energy built-up in the system from the source is about 8 times greater than the energy of the excitation for resonance $T=T_{s}$ and only about 5 times greater than the system vibration periods, which are different from the excitation oscillation periods by $\pm 20 \%$.

For better understand the phenomenon of energy transfer from the excitation to the oscillating system, here below it is an analysis of the transfer of power from the excitation to the oscillating system. The amplitude of the dissipated

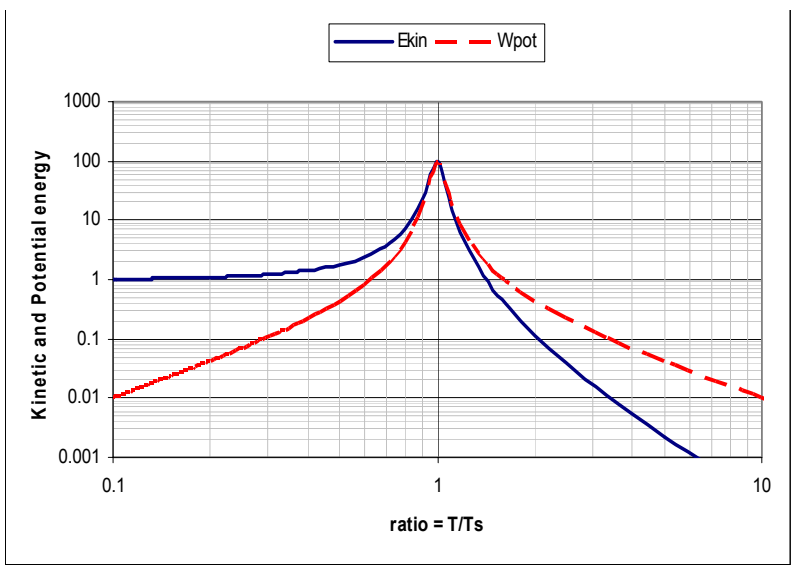

Figure 1: The kinetic and elastic amplitude energy related to excitation. The critical damping ratio is $\beta=5 \%$.

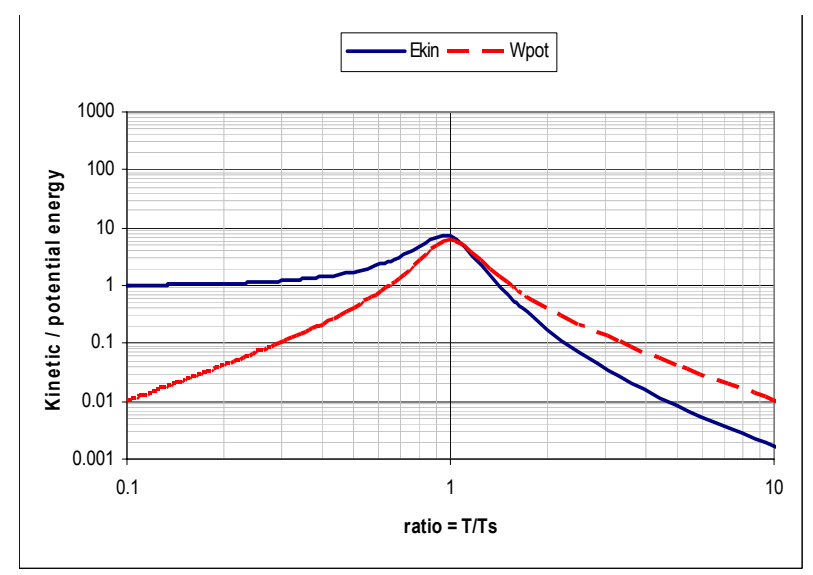

Figure 2: $\quad$ The kinetic and elastic amplitude energy related to excitation. The critical damping ratio is $\beta=20 \%$. 


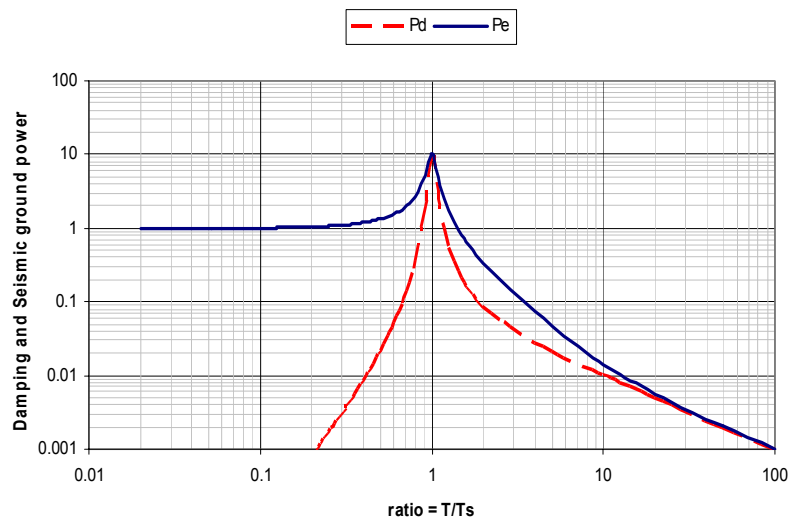

Figure 3: The power amplitude transferred from the excitation to the oscillating system and the dissipated power amplitude in the oscillating system. The critical damping ratio is $\beta=5 \%$.

power of oscillating system and of the power transferred from the excitation to the oscillating system against the system unit mass, is:

$$
\left|P_{d}\right|=\frac{2 \beta \omega \Omega^{3}}{\left(\omega^{2}-\Omega^{2}\right)^{2}+4 \beta^{2} \omega^{2} \Omega^{2}}\left|P_{s}\right|^{\prime}\left|P_{e}\right|=\sqrt{\frac{\omega^{2}+4 \beta^{2} \Omega^{2}}{\left(\omega^{2}-\Omega^{2}\right)^{2}+4 \beta^{2} \omega^{2} \Omega^{2}}} \omega\left|P_{s}\right|
$$

Figs. 3 and 4 show the amplitude variation of the power transferred from the excitation to the oscillating system and the amplitude of the power dissipated by the oscillating system for a mass unit of the oscillating system function of the ratio between the oscillating system period and the period of the excitation for $5 \%$ and $20 \%$ of the critical damping.

Analyzing the diagrams, it results that the amplitude of the power transferred from the excitation source to the oscillating system is practically equal with the amplitude of the excitation power for the oscillating system vibration periods smaller than $0.4 T_{s}$. For example, the very good behaviour of the block of flats made of prefabricated elements in Bucharest during the earthquake in 1977 is a confirmation of the phenomenon on a real case. For vibration periods greater than $0.4 T_{s}$, the oscillating system starts to build-up energy by the transferred power and the amplitude of the dissipated power reaches $1 \%$ of the excitation power amplitude (for 5\% of critical damping ratio).

\section{Technical solutions for increasing the structure, equipment and pipe network safety against dynamic actions}

Solution to control, limit and attenuate the dynamic actions upon systems consists in the elastic overtaking of the dynamic loads and their damping by means of a specific isolation device, without affecting the strength, stability and operation of the systems. 


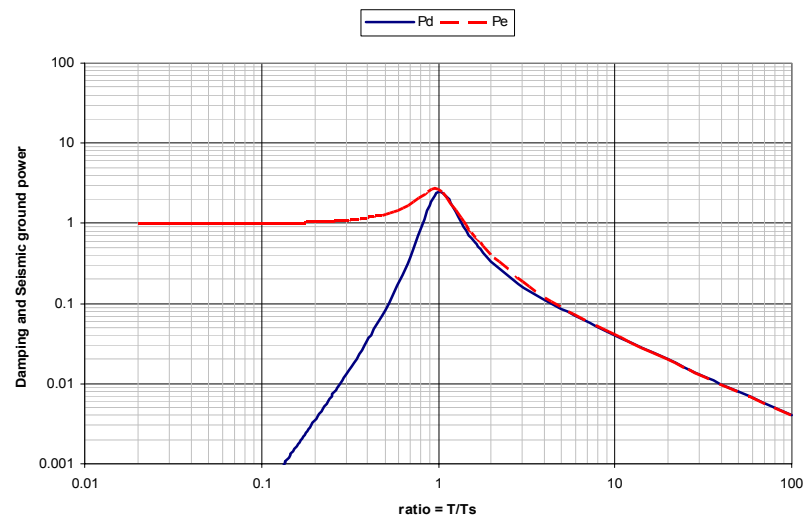

Figure 4: The power amplitude transferred from the excitation to the oscillating system and the dissipated power amplitude in the oscillating system. The critical damping ratio is $\beta=20 \%$.

To satisfy such requirements, SITON has developed a new type of devices with geometric non-linear elastic characteristics and large damping, that are capable to overtake the dynamic loads and to self-adjust to the large installation deviations and errors (Serban [1, 2], Serban et al [6]). Such a device was developed on basis of the Invention Patent no. 119845/29.04.2005 protected by OSIM and in process of being protected in the European Union.

SITON has been developing and applying the new method and technology to reduce shocks, vibrations and seismic movements in buildings, equipment and pipe networks for more than 15 years. The first industrial applications was the isolation of forging hammers (36 tons each) against shocks, vibrations and seismic movements, located in IUS SA Brasov, in 2003 (figs. 5-8) and 2004 (figs. 9-12 and Table 1), (Serban et al [8]). The operation of the isolation system in IUS-Brasov without maintenance and repairs for a period of 5 years represents a guarantee certificate for the new technology developed by SITON.

Among the performances of the system, it is worth mentioning: the $98 \%$ isolation ratios of the system; the suppression of the vibration in 1.5 oscillation cycles; the removal of the "jumping" effect; the reduction of the vibration amplitude in the near-by houses located at about $150 \mathrm{~m}$ from the production hall by more than 800 times, i.e. from $56 \mathrm{~mm} / \mathrm{sec}$ - with the old foundation isolation solution - to $0.069 \mathrm{~mm} / \mathrm{sec}$ - with SERB-SITON new foundation solution.

The isolating devices, designed and constructed in Romania, have not modified their elasticity and damping characteristics although the operation conditions are very heavy ones ( 110 blows/minute generated by a $150 \mathrm{~kg}$ forging hammer that is developing an energy of $36 \mathrm{KJ} / \mathrm{blow}$ ).

In 2006, in ROMAG-PROD the isolation of 5 electric and I and $\mathrm{C}$ cabinets, associated to the $\mathrm{H}_{2} \mathrm{~S}$ compressors by SERB-device against shocks, vibrations and earthquakes was implemented (fig. 13). 


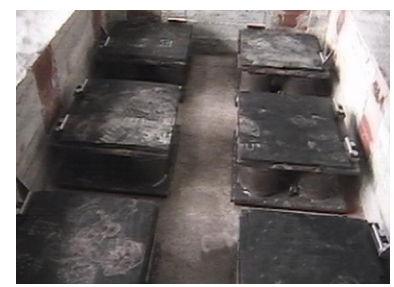

Figure 5: IUS 2003. Foundation SERB-194-3C.

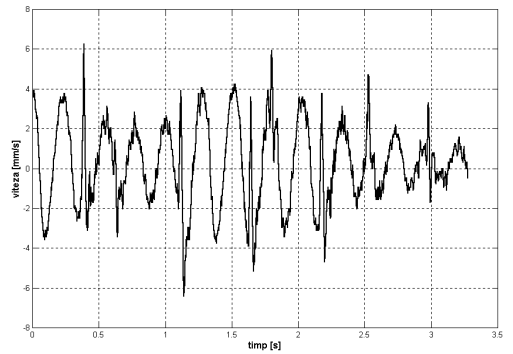

Figure 7: IUS 2003. Wave shape recorded on the foundation in the old solution.

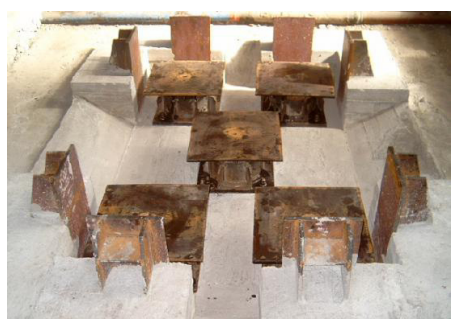

Figure 9: IUS 2004. CM1250 foundation as per SERB-375C.

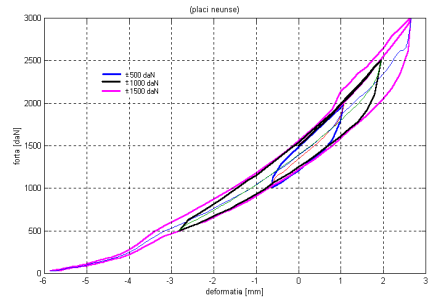

Figure 6: IUS 2003. Hysteretic curves for SERB-194-C.

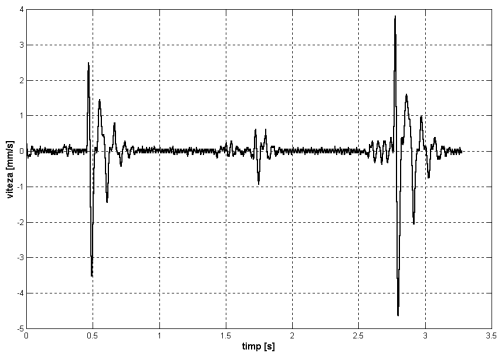

Figure 8: IUS 2003. Wave shape recorded on the foundation in the new solution.

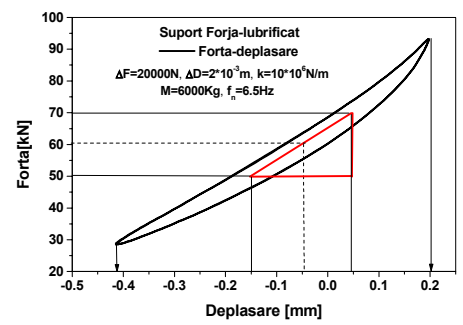

Figure 10: IUS 2004. Hysteretic characteristic for SERB$375 \mathrm{C}$. 


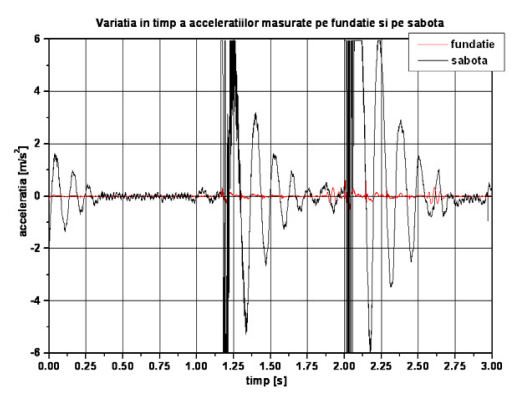

Figure 11: IUS 2004. Time history of the acceleration on isolation foundation vat (practically null line) and bed plate (black line).

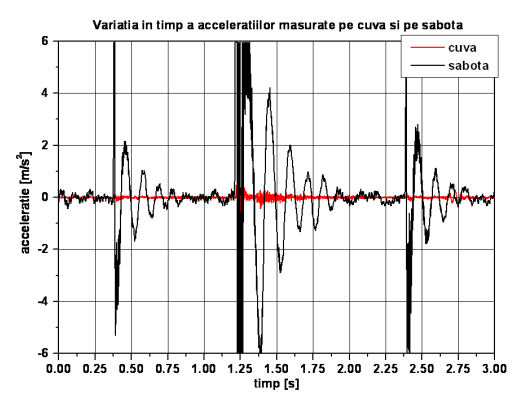

Figure 12: IUS 2004. Time history of the acceleration on isolation foundation vat (practically null line) and bed plate (black line).

Table 1: IUS 2004. The SERB-SITON isolation solution. Attenuation, transmissibility and isolation.

\begin{tabular}{|c|c|c|c|c|c|}
\hline No. & $\begin{array}{c}\text { Bed plate } \\
\text { (location } 1 \text { ) } \\
\mathrm{a}_{1}, \mathrm{~m} / \mathrm{s}^{2}\end{array}$ & $\begin{array}{c}\text { Foundation } \\
\text { (location } 2 \text { ) } \\
\mathrm{a}_{2}, \mathrm{~m} / \mathrm{s}^{2}\end{array}$ & $\mathrm{~A}=\mathrm{a}_{1} / \mathrm{a}_{2}$ & $\begin{array}{c}\mathrm{T}=\mathrm{a}_{2} / \mathrm{a}_{1} \\
\%\end{array}$ & $\mathrm{I}=\left.\right|_{0 \%} 1-\mathrm{T}$ \\
\hline 1 & 6,9 & 0,185 & 37,30 & 2,68 & 97,31 \\
\hline 2 & 3,4 & 0,067 & 50,75 & 1,97 & 98,03 \\
\hline 3 & 3,0 & 0,071 & 42,30 & 2,36 & 97,63 \\
\hline \multicolumn{5}{|c|}{ Average value } & 97,65 \\
\hline
\end{tabular}
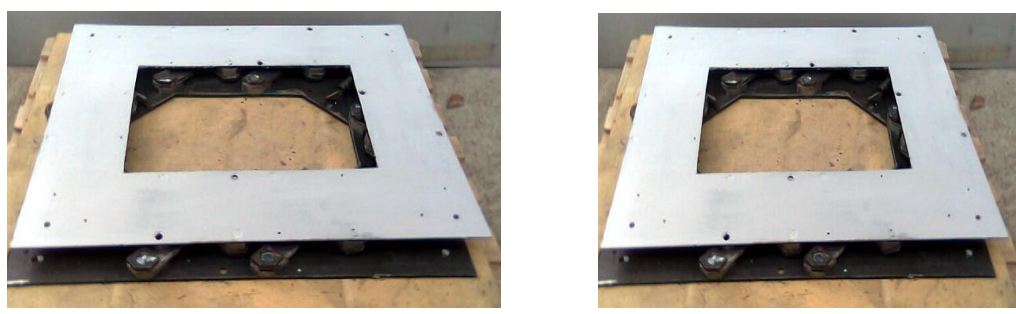

Figure 13: ROMAG-PROD. Cabinet isolation SERB device.

Also, in 2006 the most important application of SERB-SITON solution was made, namely the first nontraditional seismic strengthening of a building in Romania where the seismic loads are overtaken and damped by SERB mechanical devices installed into a network of telescopic braces and having a controlled elasticity and damping.

The strengthened building, extended and refurbished, is the Ward B in NAVROM BUSINESS CENTRE - Galati, a 6-storey building made of reinforced concrete frames, having a 3200 sqm surface and built on an old foundation supported on $12 \mathrm{~m}$ long oak wood pillars in 1923. 
The building, constructed during the period 1968-1970 and aimed to be a sailors' lodging house, was affected by the earthquakes in 1977,1986 and 1990 (fig. 14), and after strengthening and rehabilitation it is meant to house a business centre, a hotel and a restaurant.

For the quality control of SERB device, experimental tests to state the stiffness and damping characteristics were conducted on a specimen, randomly selected (fig. 15).

Due to the great damping capacity of SERB devices installed in telescopic braces (fig. 16) the seismic acceleration amplification on vertical is small, making the seismic loads and sectional stresses small.
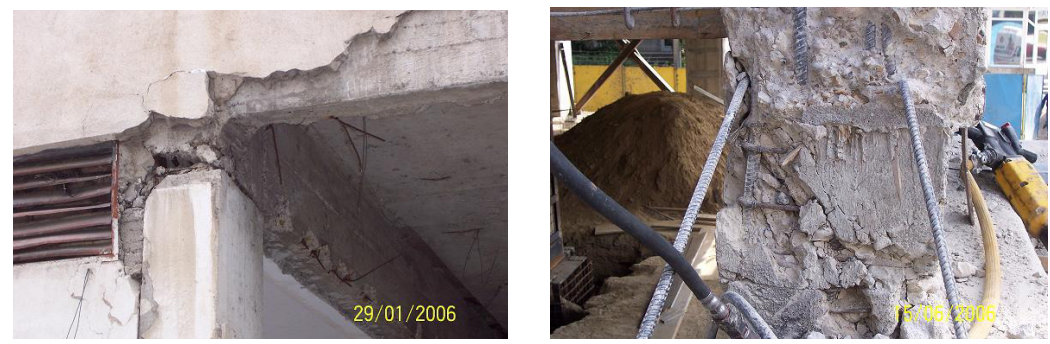

Figure 14: NAVROM Ward B. Damage of reinforced structures.
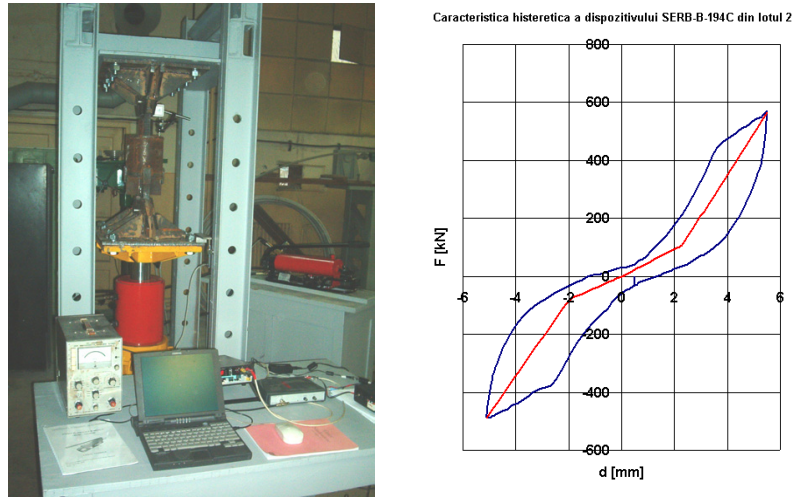

Figure 15: NAVROM. Experimental tests; hysteretic characteristic and products delivered with Batch 2 .
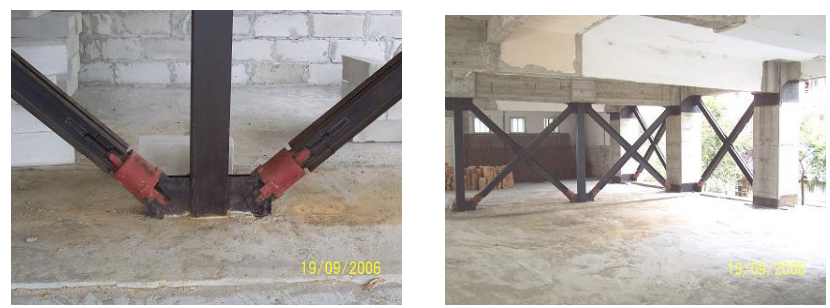

Figure 16: NAVROM Ward B. Detail of telescopic bracing anchoring metal and concrete columns. 


\section{Conclusions}

The paper is an analysis in frequency of the dynamic behaviour of an oscillating system (buildings, equipment, pipe networks, etc) on a model with one degree of freedom for to determine the dynamic response of the system in various dynamic excitation conditions. The paper points-out the fact that a system may build-up energy several times greater or smaller than the excitation energy associated to one oscillation cycle, function of the manner in which its Eigen vibration periods are situated as to dominant periods of the excitation.

The results of the analysis show that an efficient solution to reduce the dynamic response of a system is to increase the damping capacity of the system structural elements in the linear loading range.

Moreover, the results show that the most efficient method to improve the system behaviour to withstand dynamic actions is to isolate the dynamic actions or, generally, to control, limit and damp the dynamic response of the system.

According to the experimental data obtained with the industrial applications, the SERB-SITON solution used to provide the control, limit and damp against shocks, vibrations and seismic movements at buildings, equipment and pipe networks, is ranked among the most efficient solution applicable today.

\section{References}

[1] V. Serban, Brevet de inventie OSIM nr. 119845/29.04.2005, Structura sandvis, dispozitiv avand in componenta aceasta structura pentru preluarea si amortizarea incarcarilor pentru controlul comportarii unei structuri si retea de dispozitive.

[2] Agrement Tehnic nr. 016 - 03/144, Disipatori mecanici de energie seismica Tip SERB- B" Consiliu Tehnic Permanent Pentru Constructii;

[3] P 100-1/2004. Cod de proiectare seismica.

[4] V. Serban, M. Androne, G. Ciocan, M. Zamfir, C. Pavel, M. Pavel, T. Sireteanu, D. Baldovin, A.M. Mitu, C. Mohora, M. Stoica, Solutia SERBSITON De Consolidare a Cladirilor prin Izolare, a XVII-a Conferinta Nationala AICPS, Bucuresti, Romania, 1 Iunie, 2007.

[5] V. Serban, M. Androne, G. Ciocan, M. Zamfir, C. Pavel, M. Pavel, T. Sireteanu, D. Baldovin, A.M. Mitu, C. Mohora, M. Stoica, Solutia SERBSITON de Consolidare a Cladirilor prin Controlul, Limitarea si Amortizarea Deplasarilor Relative de Nivel, a XVII-a Conferinta Nationala AICPS, Bucuresti, Romania, 1 Iunie, 2007.

[6] V. Serban, M. Androne, D. Cretu, C. Pavel, M. Pavel, Controlul, limitarea si amortizarea miscarilor seismice ale unei constructii cu ajutorul dispozitivelor SERB - A 3-a Conferinta Nationala de Inginerie Seismica, Bucuresti, decembrie 2005.

[7] V. Serban, A. Panait, Isolation and Damping of Shocks, Vibrations, Impact Load and Seismic Movements at Buildings, Equipment and Pipe Networks by SERB-SITON Method - ICONE14-89189, MIAMI - FLORIDA, USA, July 2006. 